\title{
Kinematic analysis of the final stride approach in Spanish elite high jumpers
}

\author{
C. Mateos-Padorno, J. M. García-Manso, J. P. Fuentes García \& M. J. Martínez- \\ Patiño
}

To cite this article: C. Mateos-Padorno, J. M. García-Manso, J. P. Fuentes García \& M. J. Martínez-Patiño (2021): Kinematic analysis of the final stride approach in Spanish elite high jumpers, International Journal of Performance Analysis in Sport, DOI: 10.1080/24748668.2021.1908040

To link to this article: https://doi.org/10.1080/24748668.2021.1908040

$$
\text { 曲 Published online: } 08 \text { Apr } 2021 .
$$

Submit your article to this journal ¿

Q View related articles ¿

View Crossmark data $\asymp$ 


\title{
Kinematic analysis of the final stride approach in Spanish elite high jumpers
}

\author{
C. Mateos-Padorno (iD a , J. M. García-Manso (D) , J. P. Fuentes García (D) \\ and M. J. Martínez-Patiño ${ }^{c}{ }^{c}$
}

aDepartment of Physical Education, University of Las Palmas de Gran Canaria, Las Palmas, Spain; ${ }^{\text {bFaculty of }}$ Sport Sciences, University of Extremadura, Cáceres, Spain; 'Faculty of Education and Sport Science, University of Vigo, Vigo, Spain

\begin{abstract}
In high jumping, the horizontal velocity which jumpers aim to reach by the end of the run-up must be the maximum that they can control, enabling them to clear the greatest height possible. Furthermore, jumpers should reach the point of take-off with the lowest possible centre of mass (CM) to increase the thrust during take-off and thus produce a greater vertical velocity of the $\mathrm{CM}$ at the end of this phase. The aim of this study was to identify genderrelated differences in the kinematic parameters of the sprint. The sample comprised 14 high jumpers ( $n=8$ males and $n=6$ females) who were analysed during an official competition and recorded with four high speed panning cameras (sampling frequency: $50 \mathrm{fps}$ ). The results showed gender-related differences in the maximum height attained by the centre of mass during the flight phase $(p=0.004$; Effect Size $=0.93)$ and in flight effectiveness $(p \leq 0.001$; $\mathrm{ES}=5.53$ ), but not in jump effectiveness. Gender-related differences were not detected between the trajectory followed by the CM in the final supports of the run-up and the curve radius or in the direction of the final supports either. In conclusion, there are no significant gender differences in the run-up.
\end{abstract}

\section{ARTICLE HISTORY}

Received 19 September 2020 Accepted 22 March 2021

\section{KEYWORDS}

Track and field; high jump; run-up; kinematical analysis; gender differences

\section{Introduction}

The high jump is a form of athletics in which the athlete seeks to raise their centre of mass $(\mathrm{CM})$ to the maximum height $\left(H_{M a x}\right)$ at the moment of take-off with the aim of clearing a bar that has been placed at a certain height $\left(H_{B}\right)$ and which will be raised as the competition progresses. For the purpose of analysis, the high jump is usually divided into three phases: run-up, take-off phase and flight phase with bar clearance. The take-off is considered to be the key phase of the jump (Becker et al., 2013; Dapena et al., 1990; Greig \& Yeadon, 2000). The other phases of the jump are also important because they are all closely related and contribute towards the end result of the jump significantly (Coh \& Supej, 2008). A suitable run-up will enable the athlete to reach the take-off point in the correct position and at a speed high 
enough to ensure an effective jump (Dapena et al., 1990; De Pano et al., 2012). Different authors establish that a correct run-up can help the jumper to carry out a strong and efficient take-off (Dapena \& Chung, 1988; Isholeto et al., 2007). The technical problems that can occur on take-off, or even during bar clearance, are often caused by mistakes made in the run-up.

Currently, all elite high jumpers use the technique known as the Fosbury Flop, a technique made popular by Dick Fosbury in his victory at the XIX Olympic Games, held in Mexico City in 1968. The main characteristics of this technique are a run-up to the bar in a curve, or in a " $J$ " shape, and the peculiar shape adopted by the jumper when clearing the bar (backward crossing of the bar). The high jumper's aim is to achieve a speed that, when transformed into vertical thrust, enables them to clear the bar at the maximum height possible. The speed which should be reached at the end of the approach will be the maximum horizontal velocity the athlete is capable of controlling at the moment of take-off (Dapena et al., 1990; Lundin \& Berg, 1993). The characteristics of the approach, its length and the number of steps vary from one athlete to another and it depends, among other factors, on their age, sex, capabilities and performance level (Dapena, 1992; Leite, 2013; Patrick, 2001; Tellez, 1993; Tidow, 1993). Regardless of how it begins (from a stationary position to taking a few previous steps), it always includes a straight trajectory or phase followed by a curved one (Shustova et al., 2018). In the straight phase, more or less perpendicular to the bar, the speed and length of the steps or strides should increase gradually, to be directly followed by a curved portion for the final strides (between four and six) prior to take-off (Dapena et al., 1997; Schexnayder, 1994; Tellez, 1993). The consistency of both phases, their rhythmic pattern (stride length and stride frequency), the shape of the curve and the speed behaviour used (acceleration or deceleration) are some of the most important aspects that guarantee a correct jump. Many jumps depend, in part, on the transition from straight to curve.

In the curve path, a centrifugal force is generated, pushing the jumper to the outside of the curve, which is compensated by the correct lean of the athlete towards the inside of the curve. This lean is reduced progressively, to almost 0 , at the end of the take-off (Jacoby, 1987; Tidow, 1993). Its degree is different in each high jumper and in each jump, conditioned by the speed of the approach and the radius of the curve (Dapena, 1990; Mateos-Padorno et al., 2019). The amplitude of the radius of the curve (R) will determine the speed at which the jumper will finish the run-up and condition the force of take-off. Their values range from 8-12 $\mathrm{m}$ for the best male jumpers and 6-10 $\mathrm{m}$ for the best female jumpers. We should bear in mind that the optimum relationship between horizontal velocity $\left(V_{H}\right)$ and the height of the CM exists at the beginning of take-off (Dapena et al., 1993).

Neither is the curve radius and the body's inclination angle always the same during the approach to the take-off phase, rather they decrease during the final part of the run-up (Becker et al., 2013; Dapena \& Chung, 1988). $R$ becomes smaller as the athlete approaches the bar. In jumps where a greater deviation from the curve radius is observed, jumpers tend to have a lower CM (the result of the athlete's lateral inclination). If the CM is lower, its displacement is greater during take-off, which is converted into a higher vertical velocity of the CM at the end of take-off (Becker et al., 2013; Dapena et al., 1990). A higher run-up speed produces greater kinematic energy and, if the foot position is correct and the jumper has been correctly trained, greater force will be generated 
(explosive, elastic, reflex force) during take-off which, in the end, will be reflected by a more powerful take-off (Dapena \& Chung, 1988; Dapena et al., 1990; Greig \& Yeadon, 2000). In any case, the end velocity the jumper reaches, as in all other types of athletic jumps, will be conditioned by the technical prowess of the athlete. An excessive, uncontrolled velocity will result in an incorrect transformation from run-up to jump (Schexnayder, 1994), and condition the end result (Wilson et al., 2011).

At first glance, it is easy to detect the differences between male and female jumpers, which are especially clear on a biological level. Those that most affect sports performance are related to body size and composition, as well as the physiological differences that characterise each sex (Sandbakk et al., 2018). They will all be revealed by the technical and biomechanical characteristics athletes show during a high jump, which have been the subject of frequent study by different authors in top-level official competitions (Conrad \& Ritzdorf, 1986, 1988; Dapena, 1988a, 1988b; Ritzdorf et al., 1989; Bothmischel, 1990; Dapena et al., 1990; Brüggemann \& Loch, 1992; Dapena et al., 1992a, 1992b, 1993; Dapena, 1997a; Arampatzis \& Brüggemaann et al., 1999; Antekolovic et al., 2006; Dapena \& Ficklin, 2007; Coh \& Supej, 2008; Ae et al., 2008; Bermejo et al., 2012; Panoutsakopoulos \& Kollias, 2012; Bermejo Frutos et al., 2013; Nicholson et al., 2017a, 2017b, 2018; Mateos-Padorno et al., 2019).

However, it is not so frequent for such studies to focus exclusively on the detailed analysis of what occurs during the run-up (Becker et al., 2013; Dapena et al., 1997; Kahn et al., 2013; Leite, 2013; Pavlovic, 2017; Slamka \& Moravec, 1999; Tan, 1997). The link between the end of the straight portion of the run and the curved portion, as well as the end of the run-up and the beginning of the take-off, are decisive technical elements that influence the quality of the jump. In this stage, athletes must take great care with the dynamics and organisation of the foot plants without reducing the running speed. Mainly, this is when the athlete performs a series of actions that will transform the horizontal velocity of the CM into vertical velocity during the thrust (Leite, 2013). Thus, the efficiency of these actions is characterised by an increase in stride frequency (caused mainly by a reduction in flight time), step length and the correct placement of supports with respect to the bar. Of these three aspects, the length and orientation of the final two steps are the ones that show greater intra and inter-subject variability.

Less frequent has been the comparative study of this phase of the jump between jumpers of both sexes (men vs women), key to the run-up of highly trained jumpers with a good performance level during an official competition. In our case, the objective of the study was to identify the variations between male and female jumpers as a consequence of the logical potential biological differences that might exist between the components of the sample. Our hypotheses for this study were as follows: 1 . To detect any technical differences between the sexes in the take-off phase; 2 . To detect any differences between the sexes in the last steps of the run-up; and 3. To detect any differences between the sexes in the trajectory of the curve phase.

\section{Method}

\subsection{Sample}

The fourteen best finalist Fosbury Flop-style high jumpers ( 8 male and 6 female) were analysed (Men: Age $=26.04 \pm 4.35$ years of age; Standing Height $=1.91 \pm 0.04 \mathrm{~m}$; Body 
mass $=72.75 \pm 5.47 \mathrm{~kg} ;$ Personal Best Mark $=2.22 \pm 0.07$; Scoring Table IAAF $=1111.38 \pm 63.84$ points - Women: Age $=22.75 \pm 3.33$ years of age; Standing Height $=1.78 \pm 0.06 \mathrm{~m}$; Body mass $=60.17 \pm 5.08 \mathrm{~kg}$; Personal Best Mark = $1.82 \pm 0.07$; Scoring Table IAAF $=1023.50 \pm 69.80$ points) and evaluated during an official competition. From a technical perspective, the trajectory of the dominant run-up was parabolic (6 men and 4 women), while the remaining subjects performed a J-shaped run-up.

The research and all the procedures carried out were previously approved by the University of Las Palmas de Gran Canaria and the High Performance Center of San Cugat del Vallés, Barcelona (Spain) and with the support of the Royal Spanish Athletics Federation (RFEA) and the requirements of the Helsinki Declaration were met. All participants signed an informed consent form prior to the start of the study.

\subsection{Recording material}

A three-dimensional sport biomechanical analysis system (photogrammetry) was used to study the jumps. The jumps were recorded with four synchronised cameras that enabled us to record all of the phases of the run-up, regardless of the side used by the jumpers in their approach (two cameras for the jumpers who took off with their right leg and two for those who took off with their left leg). The recording was made at a speed of 50 frames per second with a resolution and image quality of $720 \times 576$ pixels and a digitisation programme (Digital Motion Capture) to capture and digitise footage. The reference systems used to obtain the three-dimensional coordinates consisted of a $1.95 \mathrm{~m}$ plastic tube with $15 \mathrm{~cm}$ separations marked on said tube. The reference was placed, before the competition, on five points of the space corresponding to the area close to the bar $(12.5 \times 8.5 \times 1.725 \mathrm{~m})$. The systematic errors accumulated by the filming system, the digitisation and processing of data were: female left-sided run-up: $0.012 \mathrm{~m}$; female right-sided run-up: $0.011 \mathrm{~m}$; male left-sided run-up: $0.011 \mathrm{~m}$; male right-sided run-up: $0.010 \mathrm{~m}$. These values were calculated by the biomechanical analysis system.

The variables evaluated in this study were as follows: radius of the curve, stride length and frequency, trajectory and orientation of the final run-up steps, efficiency of the vertical projection of the jump, flight effectiveness, contact times of the final run-up supports and the horizontal speed of the CM.

Three well-trained operators with past experience of $9.7 \pm 2.6$ years performed the observation of take-off and take-down events indecently. Inter-operator agreement was adequate according to the following Cohen's kappa $\mathrm{k}$ values: operator 1 vs. $2, \mathrm{k}=0.73$; operator $1 \mathrm{vs} 3, \mathrm{k}=0.75$; operator $2 v s .3, \mathrm{k}=0.69$, all $\mathrm{p}<0.05$. The agreement in all cases can be considered as substantial (Viera \& Garrett, 2005).

\subsubsection{Length of the last five steps and the radius of the curve phase in the run-up}

Stride length was determined by measuring the distance between the tip of the feet of two consecutive footprints. Jumpers were considered to perform a curved trajectory, with a fixed radius, between the beginning and the end of the takeoff, which responded to a radius set in accordance with the following criteria (Figure 1). 


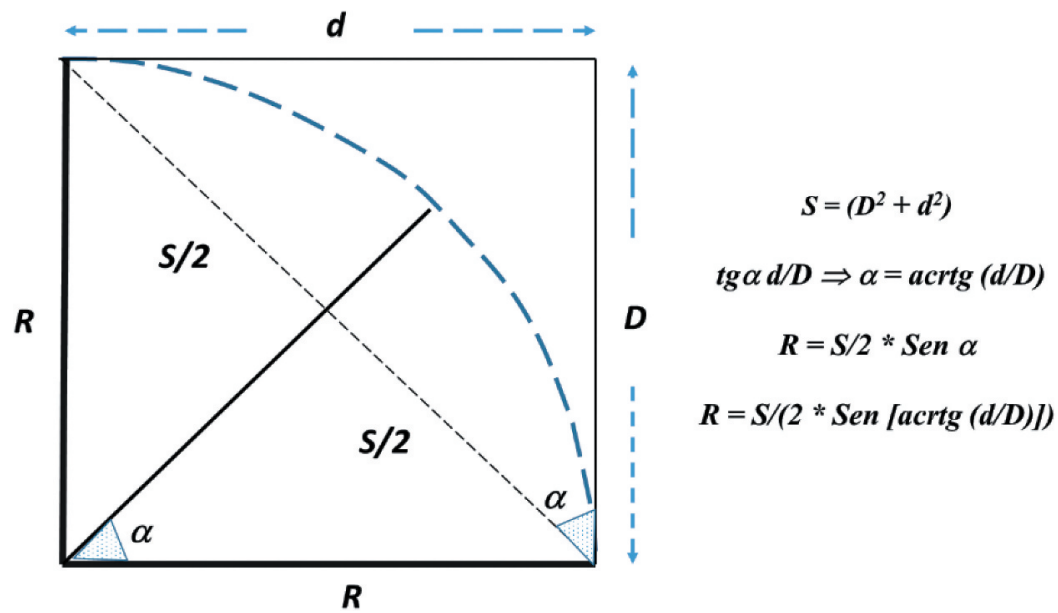

Figure 1. Methodology used to determine the theoretical radius of the last five steps of the run-up.
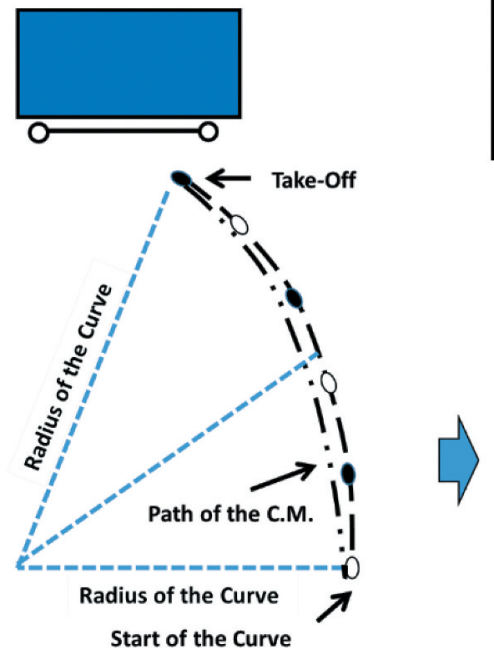
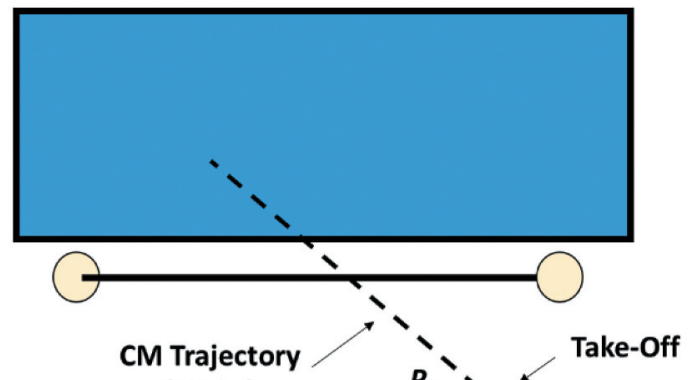

(Flight) Position of the $\mathrm{CM}$ at the end of the take-off

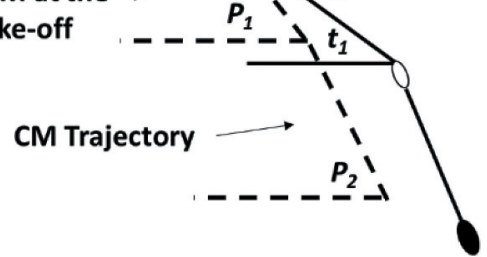

Figure 2. Example of the run-up used in the Fosbury Flop jumping technique. On the left, the radii of the curve and the trajectories of the CM (-..-) and of the footprints (--). On the right, the angles reached by the CM with the footprints during take-off preparation (Source: Dapena, 1987).

\subsubsection{Approach trajectory to the take-off point}

The efficiency of the dynamics of the final steps of the run-up makes it necessary to study their orientation with respect to the bar by measuring some of the angles identified in the specialised bibliography by the letters " $P$ " and " $t$ ", illustrated in the following figure (Figure 2). $P_{0}$ is the angle between the bar and the flight path followed by the CM after the take-off; $P_{1}$ and $P_{2}$, etc., are the angles that exist between the bar and the vertical projection of the CM during the movement of the jumper's CM during the aerial phase of the final steps. The point at which to determine the $P$ angles is made at the 
vertical projection of the CM when finishing each support (take-off). For its part, $t_{1}$ is the angle formed between the bar and the line that joins the last two footprints of the run and so on $\left(t_{2}, t_{3}\right.$, etc.).

\subsubsection{Statistical analysis}

Descriptive statistics (mean and standard deviation) were applied to the assessed parameters. Comparative statistics were also used, with different statistics for each case. In the male $v s$. female group comparison, a test of normality (Shapiro-Wilks) and a t-Student for two independent samples $(\mathrm{p} \leq .05)$ were performed. We also calculated the effect size (Cohen's d).

\section{Results}

The following table (Table 1) shows the mean values of the parameters that describe the magnitude $\left(H_{B}\right)$ and the quality of the jump $\left(H_{M a x}\right)$, the run-up radius $(R)$ and the efficiency of the vertical projection of the jump $\left(H_{M a x}-H_{B}\right)$, and the effectiveness of the flight $\left(H_{M a x}-H\right)$. Although the $R$ value is higher among the men, the difference between the groups is not statistically significant. However, significant differences are found between the two groups (men and women) with regard to the maximum height attained by the CM during the flight $(\mathrm{p}=0.004$; $\mathrm{ES}=0.93$ ) and the effectiveness of the flight ( $\mathrm{p} \leq 0.001 ; \mathrm{ES}=5.53)$. The differences in the effectiveness of the jumps are not significant $\left(H_{\text {Max }}-H_{B}\right)$.

The values that characterise the run-up (stride length and frequency, contact times and rhythm of the last five steps) are shown in the following table (Table 2). This data enables us to determine the characteristics of take-off preparation (last three steps) and the quality of the run-up rhythm used during the preparation for such an important technical element as the execution of the last support. In order to evaluate the preparation for the take-off, we take into account the penultimate support, its relation to the last step, the quickness of these movements and their adjustment to the height of the jumper. In both genders we observe a progressive reduction of the length of the last three steps which is especially relevant between the last two (difference between the penultimate and the last step $=(\hat{\jmath}): 0.23 \pm 0.08 \mathrm{~cm} ;(q): 0.13 \pm 0.02 \mathrm{~cm} ;(\mathrm{p}=0.068 ; \mathrm{ES}=0.65)$ and a slightly higher increase in men insofar as its height-adjusted value is concerned (relationship between last step and height $=102.58 \pm 5.65 \%-100.81 \pm 4.39 \%$ ), in

Table 1. Mean values and standard deviation of the radii of the curve, height cleared, real jump height and flight effectiveness.

\begin{tabular}{lcc}
\hline PARAMETER & Men (Mean \pm SD) & Women (Mean \pm SD) \\
\hline $\begin{array}{l}\text { Radius of the Curve }(\mathrm{R}) \\
(\mathrm{m})\end{array}$ & $10.83 \pm 2.02$ & $10.37 \pm 1.37$ \\
$\begin{array}{c}\text { Bar Height }\left(\mathrm{H}_{\mathrm{B}}\right) \\
(\mathrm{m})\end{array}$ & $2.15 \pm 0.07$ & $1.75 \pm 0.06$ \\
$\begin{array}{c}\text { Maximum Height CM }\left(\mathrm{H}_{\text {Max }}\right) \\
(\mathrm{m})\end{array}$ & $2.23 \pm 0.06$ & $1.85 \pm 0.09$ \\
$\begin{array}{c}\text { Effectiveness of the Jump } \\
\quad \text { Difference } \mathrm{H}_{\text {Max }}-\mathrm{H}_{\mathrm{B}}(\mathrm{cm})\end{array}$ & $0.09 \pm 0.03$ & $0.10 \pm 0.05$ \\
Effectiveness of the Flight \\
Difference $\mathrm{H}_{\text {Max }}-\mathrm{H}(\mathrm{cm})$
\end{tabular}


Table 2. Mean values and standard deviation of run-up characteristics (absolute stride length: $S L$ and relative stride length: $S \mathrm{SL} / \mathrm{H}$, stride frequency $(\mathrm{SF})$, contact time $(\mathrm{CT})$ and velocity approach ( $\mathrm{V}_{\mathrm{H}}$ C.M.).

\begin{tabular}{|c|c|c|c|c|c|}
\hline \multicolumn{6}{|l|}{ Men $(n=8)$} \\
\hline Phase - Parameter & Step -4 & Step -3 & Step - 3 & Step -1 & Step - 0 \\
\hline $\mathrm{SL}(\mathrm{m})$ & $\begin{array}{l}2.67 \\
\pm 0.27\end{array}$ & $\begin{array}{l}2.46 \\
\pm 0.24\end{array}$ & $\begin{array}{l}2.31 \\
\quad \pm 0.39\end{array}$ & $\begin{array}{l}2.18 \\
\quad \pm 0.16\end{array}$ & $\begin{array}{l}1.96 \\
\pm 0.07\end{array}$ \\
\hline $\mathrm{SL} / \mathrm{H}(\%)$ & $\begin{array}{l}140.17 \\
\pm 14.98\end{array}$ & $\begin{array}{l}128.81 \\
\pm 12.79\end{array}$ & $\begin{array}{l}121.02 \\
\pm 20.69\end{array}$ & $\begin{array}{c}114.40 \\
\pm 9.82\end{array}$ & $\begin{array}{r}102.58 \\
\pm 5.65\end{array}$ \\
\hline$S F(p / s)$ & $\begin{array}{l}2.68 \\
\pm 0.35\end{array}$ & $\begin{array}{l}2.92 \\
\quad \pm 0.39\end{array}$ & $\begin{array}{l}3.38 \\
\quad \pm 0.50\end{array}$ & $\begin{array}{l}3.73 \\
\quad \pm 0.31\end{array}$ & $\begin{array}{l}4.69 \\
\quad \pm 0.47\end{array}$ \\
\hline $\mathrm{TC}$ (ms) & $\begin{array}{l}0.38 \\
\quad \pm 0.05\end{array}$ & $\begin{array}{l}0.35 \\
\quad \pm 0.05\end{array}$ & $\begin{array}{l}0.30 \\
\quad \pm 0.05\end{array}$ & $\begin{array}{l}0.27 \\
\quad \pm 0.02\end{array}$ & $\begin{array}{l}0.22 \\
\quad \pm 0.02\end{array}$ \\
\hline$V_{H}$ C.M. $(\mathrm{m} / \mathrm{s})$ & $\begin{array}{l}6.88 \\
\quad \pm 0.67\end{array}$ & $\begin{array}{l}7.05 \\
\quad \pm 0.60\end{array}$ & $\begin{array}{l}7.07 \\
\pm 0.54\end{array}$ & $\begin{array}{l}7.36 \\
\quad \pm 0.72\end{array}$ & $\begin{array}{l}6.97 \\
\quad \pm 0.38\end{array}$ \\
\hline \multicolumn{6}{|l|}{ Women $(n=6)$} \\
\hline Phase - Parameter & Step - 4 & Step - 3 & Step - 3 & Step -1 & Step - 0 \\
\hline $\mathrm{SL}(\mathrm{m})$ & $\begin{array}{l}2.32 \\
\quad \pm 0.26\end{array}$ & $\begin{array}{l}2.34 \\
\quad \pm 0.26\end{array}$ & $\begin{array}{l}1.94 \\
\quad \pm 0.20\end{array}$ & $\begin{array}{l}1.86 \\
\quad \pm 0.08\end{array}$ & $\begin{array}{l}1.75 \\
\quad \pm 0.11\end{array}$ \\
\hline $\mathrm{SL} / \mathrm{H}(\%)$ & $\begin{array}{l}130.16 \\
\pm 13.19\end{array}$ & $\begin{array}{l}131.34 \\
\pm 12.51\end{array}$ & $\begin{array}{l}109.01 \\
\quad \pm 11.03\end{array}$ & $\begin{array}{l}104.59 \\
\pm 5.53\end{array}$ & $\begin{array}{l}98.22 \\
\quad \pm 6.91\end{array}$ \\
\hline$S F(p / s)$ & $\begin{array}{l}2.52 \\
\quad \pm 0.49\end{array}$ & $\begin{array}{l}2.59 \\
\quad \pm 0.48\end{array}$ & $\begin{array}{l}3.24 \\
\pm 0.43\end{array}$ & $\begin{array}{l}3.32 \\
\quad \pm 0.38\end{array}$ & $\begin{array}{l}4.67 \\
\quad \pm 0.90\end{array}$ \\
\hline $\mathrm{TC}(\mathrm{ms})$ & $\begin{array}{l}0.41 \\
\quad \pm 0.08\end{array}$ & $\begin{array}{l}0.38 \\
\quad \pm 0.05\end{array}$ & $\begin{array}{l}0.31 \\
\quad \pm 0.05\end{array}$ & $\begin{array}{l}0.30 \\
\quad \pm 0.02\end{array}$ & $\begin{array}{l}0.22 \\
\quad \pm 0.02\end{array}$ \\
\hline $\mathrm{V}_{\mathrm{H}}$ C.M. $(\mathrm{m} / \mathrm{s})$ & $\begin{array}{l}5.76 \\
\quad \pm 0.61\end{array}$ & $\begin{array}{l}6.04 \\
\quad \pm 0.73\end{array}$ & $\begin{array}{l}5.99 \\
\pm 0.44\end{array}$ & $\begin{array}{l}6.03 \\
\quad \pm 0.79\end{array}$ & $\begin{array}{l}6.47 \\
\pm 0.45\end{array}$ \\
\hline
\end{tabular}

Table 3. Mean values and standard deviation of the direction of the footprints $(t)$ and the direction of the path of the C.M. (P) during the last five steps (Step-0 to Step- 4 ) for both groups.

\begin{tabular}{lccccc}
\hline Men $(\mathrm{n}=8)$ & & & & \\
\hline Phase - Parameter & Step -4 & Step -3 & Step -3 & Step -1 & Step - 0 \\
\hline Ángulo - $P_{4-0}$ & - & - & $38.13 \pm 5.49$ & 39.75 & 38.13 \\
& & & \pm 3.06 & \pm 5.49 \\
Ángulo - $t_{3-1}$ & 85.00 & 75.13 & $64.63 \pm 6.57$ & 52.38 & 24.25 \\
& \pm 2.14 & \pm 3.68 & & \pm 5.45 & \pm 5.44 \\
Women $(\mathrm{n}=6)$ & & & & & \\
Phase - Parameter & Step - 4 & Step - 3 & Step - 3 & Step -1 & Step - 0 \\
Ángulo - $P_{4-0}$ & - & - & 37.33 & 37.67 & 37.33 \\
& & & \pm 4.08 & \pm 10.01 & \pm 4.82 \\
Ángulo - $t_{3-1}$ & 86.17 & 76.33 & 64.17 & 53.50 & 24.17 \\
& \pm 3.13 & \pm 6.44 & \pm 8.80 & \pm 7.04 & \pm 5.64 \\
\hline
\end{tabular}

frequency and in the index corresponding to the quality of the rhythm of the final foot plants $\left(M_{R}\right)$. This index relates the increase in the stride frequency $\left(I_{F}\right)$ of the last three foot plants to the arithmetic average of the length of the last four steps $\left(S L_{F}\right)(0.08$ and 0.12 , respectively).

Table 3 shows the characteristics of the trajectory followed by the jumpers during the curve phase of the run-up and, in particular, the preparation for the take-off $(P$ and $t$ angles during the last five steps). The differences between the two groups show no statistically significant differences. It should be noted that there is scarcely any relationship between the trajectory of the CM in the final foot plants $(P)$ and the curve radius $(\delta$ : $\left.P_{2}=-0.98 ; P_{1}=0.86: P_{0}=0.36 ;+P_{2}=-0.74 ; P_{1}=-0.62: P_{0}=0.35\right)$. A similar behaviour, although more irregular, can be observed with regard to the orientation of the final foot plants $(t)\left(\hat{O}: t_{3}=0.87 ; t_{2}=0.69: t_{1}=0.53 ;\right.$; $\left.: t_{3}=0.35 ; t_{2}=0.47: t_{1}=0.54\right)$. 
It can also be observed that the mean values of these angles fall within the normal range in the male sample, but not in the female sample, where they are not consistent with the values specialists propose. We would point out that the $P_{0}$ size is practically the same as the $P_{1}$ value, which might make it impossible to achieve the angular position needed to clear the bar and which, along with the short take-off time used by these jumpers, results in the reduced possibility of developing or applying the force necessary in order to increase the vertical velocity at the moment of take-off.

\section{Discussion}

With respect to the first hypothesis which made reference to the possible technical differences involved in the take-off phase, we can confirm that significant differences were indeed detected between the groups (men and women) regarding both the maximum height attained by the CM during the flight and the effectiveness of the flight itself, although significant differences in the effectiveness of the jumps were not verified.

Insofar as the second hypothesis, regarding the behaviour of the final run-up steps, is concerned, we can confirm that no significant differences between the two groups were found. Both categories showed a progressive reduction in the last three steps, which was especially relevant between the last two steps; a similar behaviour between the men and the women in relation with the stride frequency and contact times at the end of the runup was also observed.

With respect to the third hypothesis, which referred to the trajectory of the curve phase, we can corroborate that no significant differences between the two groups were found.

In light of these data, it can be seen that no clear and significant differences exist between the run-ups performed by the male and the female jumpers. These differences are based on two main aspects: the biological differences typical of both sexes (especially the morphological and physical differences) and those that stem from the technical level of each group's components. It is natural, then, that the male jumpers show higher, and significantly different, height and body weight values than the female athletes. This circumstance influences the range of stride during the two phases of the run-up (straight and curve) and, possibly, the curve radius. The $R$ value for both groups falls within the values that usually correspond to individuals of the level studied (H: $9.00-13.00 \mathrm{~m} v \mathrm{~s}$. M: 7.00-11.00 m), which, as occurs between athletes from our sample, are highly trained individuals with a high performance level. In both groups, the radii show clear and statistically significant differences.

It is a fact that the radius is directly related to the speed at which the athlete enters the take-off and that this, in turn, influences the height of the jump (Primakov et al., 1986). International-level athletes show a run-up speed that ranges from 7.0 to $8.3 \mathrm{~m} / \mathrm{s}$ in male jumpers (Dapena et al., 1992b; Dapena \& Ficklin, 2007; Isholeto et al., 2007; Nicholson et al., 2019, 2017a, 2018; Venkateswara-Rao \& Raja-Rao, 2016) and from 6.1 to $7.2 \mathrm{~m} / \mathrm{s}$ in female jumpers (Brüggemann \& Loch, 1992; Challis \& Yeadon, 1992; Blažević et al., 2006; Panoutsakopoulos \& Kollias, 2012; Dapena et al., 2007; Nicholson et al., 2017b). Hongfei (1987) points out that the ex-world record holder, the Chinese athlete Zhu Jianhua $(2.39 \mathrm{~m})$, entered the take-off at a speed of $8.70 \mathrm{~m} / \mathrm{s}$ for a $2.38 \mathrm{~m}$. jump and $8.73 \mathrm{~m} / \mathrm{s}$ for a $2.37 \mathrm{~m}$ jump. However, these speeds are surprisingly high if we recur to the data that 
commonly appear in specialised bibliographies, where we rarely find a jumper capable of entering at a speed similar to or higher than $8.00 \mathrm{~m} / \mathrm{s}$. Usually, only the best male jumpers, with personal bests of higher than $2.35 \mathrm{~m}$, habitually equal or exceed a speed of $8.00 \mathrm{~m} / \mathrm{s}$, while the best female jumpers usually exceed a speed of $7.00 \mathrm{~m} / \mathrm{s}$ in order to perform jumps of over $1.90 \mathrm{~m}$, which represents a difference of around 6-8 \% between the sexes. Initially, the higher the level of the athlete, the higher the horizontal velocity at which the jumper enters the take-off should be (Hongren et al., 2019).

The way in which speed develops during the run-up is a key element for the effectiveness of the jump and a decisive aspect of the jumper's technical level (Stefanović, 2015). Although, theoretically, the ideal technique would involve increasing the speed up until the moment of take-off, in practice a moderate loss of speed between the second-last and last step is usually observed (Primakov et al., 1986). In our sample, the men showed an increase in speed up until the second-last step with a slight decrease in the last step $(7.36 \pm 0.72 \mathrm{~m} / \mathrm{s}$ vs. $6.97 \pm 0.38 \mathrm{~m} / \mathrm{s})$. This behaviour was not detected in the female athletes, where only two reached their maximum speed in the second-last step.

Even if we accept that the penultimate step must usually be quicker, the level of the drop in speed in the last step shows significant individual differences. In our study, the loss of speed stood at $0.37 \mathrm{~m} / \mathrm{s}$ for the male athletes. These values are very high in comparison with those found in other studies carried out on international-level jumpers, where there were clearly fewer examples of speed losses. With regard to the female athletes, the speed loss tends to be similar or, in some cases, even increases. We are in a position to affirm that whenever the speed increases at the end of the run-up or the speed losses that occur are minimal, the speed rhythm of the jumper is good. In the case of the females in our sample, the speed does not increase progressively but in stages. However, in the last step they are able to increase their speed because it is very low prior to this point and, therefore, easier to increase, although we believe fictitiously, and has negative consequences for the flight towards the bar, the result of a lack of preparation and control over the speed.

In any case, the rhythmic pattern in the last two steps should be aimed at achieving an efficient transformation of the horizontal and vertical speed components during the takeoff (Panoutsakopoulos \& Kollias, 2012). The changes in the horizontal speed of the runup are accompanied by modifications in its determining aspects: stride frequencies $(S F)$, support time of each plant (TC), length between two successive plants $(S L)$ and angle of the run-up and the final plants $(P$ and $t)$.

The length of the last two steps usually shows a specific behaviour, both in female and male athletes, revealed, as occurs in our study, by a progressive reduction up to the take-off point (Pavlovic, 2017). In our study, this behaviour is very clear among the male athletes but less stable and progressive among the females, which could be interpreted as a technical difference between the two groups. What occurs in the last two strides is especially important. Bothmischel (1990) considers that the length of the last stride must be a foot shorter, a condition which is not met in our study, especially in the female athletes. The differences in SL are determined, mainly, by height $(\mathrm{H})$, which is why the SL/H index can be considered a sound technical indicator. From this perspective, the differences that exist between the male and female high jumpers in our group do not show statistically significant differences. In the last step, the $\mathrm{SL} / \mathrm{H}$ index was $98.7 \pm 6.5 \%$ for the females and $102.6 \pm 5.7 \%$ for the males, which represents similar values to those found by $\mathrm{Xu}$ and Liu 
(2005) in international-level jumpers (86.6\% vs. 103.2\%). However, the SL/H index values are slightly lower than those observed in the different studies that exist in specialised bibliographies (108-112\%, or even lower still, for the male athletes, as opposed to the $103-105 \%$ for the females). Different behaviour can be detected between the male and female athletes with regard to stride frequency. While our male high jumpers increased their SF progressively as they approached the take-off, the females showed an irregular increase up to the last step. We could approach this difference, as occurred with the SL/SF relationship, as just one more aspect of the technical level of both groups. This explains, to a large extent, the speed behaviour during the approach to the take-off. A significant increase in SF in the last step indicates a more active action of the foot plants and a change in the running mechanics in order to prepare for the take-off. According to Strizhak et al. (1989), the stride frequency must increase progressively in the last strides of the run-up before the thrust, to reach values of 4.8-5.0 steps/second for the male athletes and somewhat higher (5.0-5.5 steps/second) for the females. In our sample, despite the significant increase observed in the final steps, the maximum values are slightly lower than the values of reference mentioned. The behaviour of these two parameters (SL and SF) shows the rhythmic structure of the run-up. The $M_{R}$ index in our study is much higher $(31.8 \%)$ for the female athletes as a result of a possibly inefficient increase in the frequency of the jumpers' final steps.

Another effect of the modification of the SL and SF values during the curve phase of the run-up can be observed from the duration of the contact times (TC) Either because the withdrawal of the foot plants occurs too soon or because they are too rigid, the TC value tends to decrease as the jumper reaches the bar. The longer the duration of a plant, the softer the contact with the ground and, logically, the less reactive the thrust attained in each one. With regard to both the male and female athletes, our study indicates a progressive decrease in the duration of the foot plants which correlates inversely with SF and SL. Especially noteworthy is the fact that the relationships between SF and TC are practically the same in the two groups in our study. We understand that the TC of the two groups is excessively long when compared to the values we can find in specialised bibliographies.

Another relevant aspect when comparing the run-up is the trajectory that follows the plants during the curve phase, as well as the trajectory of the CM and body position. Contrary to what might be thought initially, the footprints in the curve phase do not follow an arch with a fixed radius, rather it decreases progressively. Once a jumper enters the curve phase, the angle formed by their trajectory (CM and foot plants in the curve) with the prolongation of the bar must decrease progressively up until the athlete reaches the take-off point, with special incidence in the final steps. During the straight phase of the run-up, the CM travels directly upon the footprints marked by the supports, while in the curve phase, where the athlete needs to lean towards the interior of the path, the CM is displaced away from the supports or, in other words, it travels closer to the centre of the curve than the footprints themselves. At the end of the run-up, both paths tend to converge again, in such a way that the CM is positioned almost on top of the take-off foot at the end of the take-off, although its trajectory is tangential to the plane of the bar. One consequence of this behaviour is that the final $\mathrm{CM}$ trajectory angle $\left(P_{0}\right)$ is always greater than the angle corresponding to the merging of the trajectory of the last two steps $\left(t_{1}\right)$, with a value of $10^{\circ}-15^{\circ}$ (Dapena et al., 1997; Mateos-Padorno et al., 2019). Furthermore, the values proposed by Dapena (1988) with regard to the direction of the last three steps before the 
take-off stand at $46^{\circ}-73^{\circ}$ for the ante-penultimate stride $\left(P_{2}\right), 46^{\circ}-61^{\circ}$ for the penultimate stride $\left(P_{1}\right)$ and $27-38^{\circ}$ for the last stride $\left(P_{0}\right)$. It is equally important to evaluate the last step in order to verify whether the jumper places their foot too parallel to the bar, as this could be dangerous for the ankle joint during the damping phase of the take-off; the foot undergoes important deformations which affect the tibiotarsal joint, frequently leading to common injuries in high jumpers (Mateos Padorno, 2003).

The values corresponding to the trajectory of the CM insofar as the male sample is concerned shows similar data to the values of reference that can be found in specialised bibliographies, except concerning the trajectory of the $\mathrm{CM}$ at the moment of take-off, whose value increases significantly. Something similar occurs with the behaviour observed in the sample of females in our study. However, lower values are detected in the angle formed by the trajectory of the CM in each one of these last three steps. This could lead us to believe that the female jumpers do not perform their supports in the curve phase in the appropriate direction, that is, moving away from the centre of the curve. This means that they are not pushing downwards and to the right, in the case of jumpers who take-off with their left foot. Furthermore, the data indicate that, in the take-off, the application of forces compromises the statics of the last support.

The difference between $t_{1}$ and $P_{0}$ is approximately $15^{\circ}\left(\delta^{\Uparrow}\right), 13^{\circ}(+)$, which shows a significant lateral inclination of the torso towards the inside of the curve despite the relatively low speed at which the individuals in our study move. In the case of the female athletes, the values obtained are lower, indicating a less-pronounced inclination of the torso during movement. This is normal bearing in mind the difference in speed that exists between the two groups.

\section{Conclusion}

No significant differences between the male and female athletes were detected in the runup variables studied, that is, run-up radius, stride length and frequency, step direction and the trajectory of foot plants. With respect to take-off, significant differences were found in the jump height and flight effectiveness, although not in the effectiveness of the jump. The differences found are in line with the logical morphological differences of the two sexes and, to a certain extent, with the differences in technique and performance that exist between the two groups.

\section{Disclosure statement}

No potential conflict of interest was reported by the authors.

\section{ORCID}

C. Mateos-Padorno (D) http://orcid.org/0000-0003-2406-6031

J. M. García-Manso (iD http://orcid.org/0000-0002-4360-3384

J. P. Fuentes García (D) http://orcid.org/0000-0002-8299-1092

M. J. Martínez-Patiño (D) http://orcid.org/0000-0003-2721-9240 


\section{References}

Ae, M., Nagahara, R., Ohshima, Y., Koyama, H., Takamoto, M., \& Shibayama, K. (2008). Biomechanical analysis of top three male high jumpers at the 2007 World Championships in Athletic. New Studies in Athletics, 23(2), 45-52.

Antekolovic, L., Blazevic, I., Mejovsek, M., \& Coh, M. (2006). Longitudinal follow-up of kinematic parameters in the high jump - A case study. New Studies in Athletics, 21(4), 27-37.

Arampatzis, A., \& Brüggemaann, G.P. (1999). High Jump. In D. Koszewski, G-P. Brüggemann, H. Müller (eds). Biomechanical Research Project Athens 1997. Final Report. Oxford Meyer \& Meyer Sport (UK) Ltd, 1999, 130-144.

Becker, J., Kerin, D., \& Chou, L. S. (2013). Consequences of deviation from the curve radius in the high jump approach. In 31 International Conference on Biomechanics in Sports, Tapei, Taiwan.

Bermejo Frutos, J., López Elvira, J. L., \& Palao Andrés, J. M. (2013). Gender differences in high jump according to age categories. Apunts. Educación Física Y Deportes, 111(111), 62-69. http:// doi.org/10.5672/apunts.2014-0983.es.(2013/1).111.06

Bermejo, J., Palao, J. M., \& Elvira, J. L. (2012). Kinematic differences between Spanish and international high jumpers. Cultura, Ciencia y Deporte, 7(21), 179-190. https://doi.org/10. 12800/ccd.v7i21.83

Blažević, I., Antekolović, L., \& Mejovšek, M. (2006). Variability of high jump kinematic parameters in longitudinal follow-up. Kinesiology, 38(1), 63-71. https://hrcak.srce.hr/4118

Bothmischel, V. E. (1990). Model characteristics of the high jump approach. Modern Athlete and Coach, 28(4), 3-6.

Brüggemann, G., \& Loch, M. (1992). The scientific research project at the III world championships in athletics: High jump. New Studies in Athletics, 7(1), 67-74.

Challis, S., \& Yeadon, F. (1992). A biomechanical analysis of the women's high jump. Athletics Coach, 26(2), 20-25.

Coh, M., \& Supej, M. (2008). Biomechanical model of the take-off action in the high jump: A case study. New Stud Athlet, 23(4), 63-73.

Conrad, A., \& Ritzdorf, W. (1986). High jump: Results of a biomechanic study. Extract from thc scientific report ofthe IAA F biomechanic research on the flrst world junior championships. New Studies in Athletics, 1(4), 33-51.

Conrad, A., \& Ritzdorf, W. (1988). Biomechanical analysis of the high jump. In In G.-P. Brüggemann, B. Glad (Eds.), Scientific Research Project at the Games of the XXIVth Olympiad - Seoul 1988, Final Report (pp 177-217). Monaco: International Athletic Foundation.

Dapena, J. (1987). Basic and applied research in the biomechanics of high jumping. Current Research in Sports Biomechanics, Eds. B. Van Gheluwe and J. Atha. Karger, Basel, 19-33.

Dapena, J. (1988a). Biomechanical analysis of the Fosbury-flop. Track Technique, 105, 3343-3350.

Dapena, J. (1988b). Biomechanical analysis of the fosbury flop. Track Technique, 104, 3307-3317.

Dapena, J. (1990). Introduction to the biomechanics of high jumping. In First International Conference on Techniques in Athletics (pp. 309-321), Cologne.

Dapena, J. (1992). Biomechanical studies in the high jump and the implications to coaching. Track and Field Quarterly Review, 92(4), 34-38.

Dapena, J. (1997a). A closer look at the shape of the high jump run-up. Track Coach, 138, 4406-4411.

Dapena, J., Ae, M., \& Iiboshi, A. (1997). A closer look at the shape of the high jump run-up. Track Coach, 138, 4406-4411.

Dapena, J., Angulo, R. M., Caubet, J. M., Turró, C., Balius, X., Kinzler, S. B., Escoda, J., \& Prat, J. A. (1992a). Track and field high jump: Women. Report for the International Olympic Committee. Medical Comission: Biomechanics Subcomission.

Dapena, J., Angulo, R. M., Caubet, J. M., Turró, C., Balius, X., Kinzler, S. B., Escoda, J., \& Prat, J. A. (1992b). Track and Field High jump: Women. Report for the International Olympic Committee. Medical Comission: Biomechanics Subcomission. 
Dapena, J., \& Chung, C. S. (1988). Vertical and radial motions of the body during the take-off phase of high jumping. Medicine and Science in Sports and Exercise, 20(3), 290-301. https://doi. org/10.1249/00005768-198806000-00014

Dapena, J., \& Ficklin, T. K. (2007). High jump. Scientific services project (USA). Biomechanics Laboratory, Dept. of Kinesiology, Indiana University.

Dapena, J., McDonald, C., \& Cappaert, J. (1990). A regression analysis of high jumping technique. Journal of Applied Biomechanics, 6(3), 246-261.

Dapena, J., Vaughn, R. E., \& Johnston, G. L. (1993). High jump (Men). USA Track \& Field. Olympic Committee, Indianápolís, Scientific Report of the American Olympic Classification Tests

De Pano, A., Matas, X. B., \& Soler, F. C. (2012). Aplicación del análisis fotogramétrico al salto de altura. RED: Revista de Entrenamiento Deportivo, 26(1), 5-10. https://g-se.com/aplicacion-delanalisis-fotogrametrico-al-salto-de-altura-1579-sa-r57cfb272315a1

Greig, M. P., \& Yeadon, M. R. (2000). The influence of touchdown parameters on the performance of a high jumper. Journal of Applied Biomechanics, 16(4), 367-378. https://doi.org/10.1123/jab. 16.4.367

Hongfei, H. (1987). Approches et envolées rapides. La Technique De Zhu Jianhua, AEFA, France, 101, 59-62.

Hongren, C., Zhiquan, J., Tinggang, Y., Zili, J., \& Guojie, W. (2019). Research on key sports techniques of world class elite men's high jumpers. China Sport Science and Technology, 55(9), 52-59.

Isholeto, J., Virmavirta, M., Kyrolainen, H., \& Komi, P. (2007). Biomechanical analysis of the high jump at the 2005 IAAF world championships in athletics. New Studies in Athletics, 22(2), 17-27.

Jacoby, E. (1987). A guide to the flop high jump approach. Track and Field Quarterly Review, 87(4), 39-45.

Kahn, A., Hussain, I., \& Mohammad, A. (2013). Effect of different joints velocity during approach run on high jumping performance: A kinematic study. Middle-East Journal of Scientific Research, 18(1), 22-25. https://doi.org/10.5829/idosi.mejsr.2013.18.1.11197

Leite, W. (2013). Biomechanical analysis of running in the high jump. Pedagogics, Psychology, Medical-Biological Problems of Physical Training and Sports, 17(2), 99-105. https://sportpedagogy.org.ua/index.php/PPS/article/view/600

Lundin, P., \& Berg, W. (1993). Approach development in the jumps. New Studies in Athletics, 8(1), 45-50.

Mateos Padorno, C. (2003). Análisis y descripción de la carrera de impulso y de batida en el salto de altura estilo fosbury-flop. Estudio de una muestra de saltadores españoles de máximo nivel [Doctoral Dissertation]. Universidad de Las Palmas de Gran Canaria.

Mateos-Padorno, C., García-Manso, J. M., Martínez-Patiño, M. J., \& Valverde-Esteve, T. (2019). Analysis of effectiveness of free segment actions and antero-posterior and lateral body displacements during the take-off phase of high jump (flop style). International Journal of Performance Analysis in Sport, 19(1), 14-27. https://doi.org/10.1080/24748668.2018.1555737

Nicholson, G., Bennett, T., Bissas, A., \& Merlino, S. (2019). Biomechanical report for the IAAF world indoor championship London 2018. High Jump Men.

Nicholson, G., Bissas, A., \& Merlino, S. (2017a). Biomechanical report for the IAAF world championship 2018. High Jump Men's.

Nicholson, G., Bissas, A., \& Merlino, S. (2017b). Biomechanical report for the IAAF world championship 2018. High Jump Men's.

Nicholson, G., Bissas, A., \& Merlino, S. (2018). Biomechanical report for the IAAF world indoor championship London 2017. High Jump Men.

Panoutsakopoulos, V., \& Kollias, I. A. (2012). 3D biomechanical analysis of women's high jump technique. New Studies in Athletics, 27(3), 31-44.

Patrick, S. (2001). High jump: Technical aspects. Track Coach, 155, 4938-4940. 
Pavlovic, R. (2017). The differences of kinematic parameters high jump between male and female finalists world championship Daegu, 2011. Turkish Journal of Kinesiology, 3(4), 60-69. ISSN Number: 2459-0134

Primakov, I. N., Lazarev, I. V., \& Konestiapin, V. G. (1986). Salto de altura. In J. C. Álvarez \& M. Vélez (Eds.), Facultad de Capacitación Profesional del Instituto Central de Educación Física Orden de Lenin (Moscú). Spanish traslation (pp. 1986). CAR.

Ritzdorf, W., Conrad, A., \& Loch, M. (1989). Intra-individual comparison of the jumps of Stefka Kostadinova at the II world championships in athletics Rome 1987 and the games of the XXIV olympiad Seoul 1988. New Studies in Athletics, 4(4), 35-41.

Sandbakk, Ø., Solli, G. S., \& Holmberg, H. C. (2018). Sex differences in world-record performance: The influence of sport discipline and competition duration. International Journal of Sports Physiology and Performance, 13(1), 2-8. https://doi.org/10.1123/ijspp.2017-0196

Schexnayder, I. (1994). Special considerations for the high jump approach. Track Coach, 126, 4029-4031.

Shustova, E. V., Kulishenko, I. V., \& Shustov, A. A. (2018). Modern trends in elite high jumpers"running start improvement domain. Theory and Practice of Physical Culture, (3), 24. ISSN: 2409-4234

Slamka, M., \& Moravec, R. (1999). Optimization of run-up speed in the women's high jump. Acta Facultatis Educationis Physicae Universitatis Comenianae, 40, 193-202.

Stefanović, R. (2015). Annex to the training techniques high jump: Fosbury-Flop. Activities in Physical Education \& Sport, 5(2), 227-230.

Strizhak, A. P., Aleksandrov, O. I., Sidorenko, S. P., \& Petrov, V. A. (1989). Lehkoatleticheskie Pryzhki. Health.

Tan, J. C. (1997). The mechanics of the curved approach in high jumping [doctoral dissertation]. Loughborough University.

Tellez, K. (1993). Elements of the high jump. Track Coach, 125, 3987-3990.

Tidow, G. (1993). Model technique analysis-part VIII: The flop high jump. New Studies in Athletics, 8(1), 31-44.

Venkateswara-Rao, C., \& Raja-Rao, C. (2016). Kinematic analysis of take off technique on the performance of the Fosbury Flop. Journal of Sports and Physical Education, 3(3), 17-20. https:// doi.org/10.9790/6737-03031720

Viera, A. J., \& Garrett, J. M. (2005). Understanding interobserver agreement: The Kappa statistic. Family Medicine, 37(5), 360-363.

Wilson, C., King, M. A., \& Yeadon, M. R. (2011). The effects of initial conditions and takeoff technique on running jumps for height and distance. Journal of Biomechanics, 44(12), 2207-2212. https://doi.org/10.1016/j.jbiomech.2011.06.010

Xu, W., \& Liu, M. (2005). Kinematic analysis of the run up final stride and take-off technique in chinese female Fosbury Flop jumpers. Proceedings of 2005 Symposium of the International Society of Biomechanics in Sports (pp. 447-448), Konstanz, Germany. 